\title{
Determinants of Motivation among Health Care Providers, Case of Four General Referral Hospitals in Lubumbashi
}

\author{
Banza Mwana Bute1, Malulu Kabwe Djaile', Kabamba Wa Kabamba Christian², \\ Ilunga Kandolo Simon ${ }^{3 *}$, Kabyla Ilunga Benjamin² \\ ${ }^{1}$ Higher Institute of Medical Technics, Manono, Democratic Republic of Congo \\ ${ }^{2}$ Faculty of Medicine, University of Lubumbashi, Lubumbashi, Democratic Republic of Congo \\ ${ }^{3}$ School of Public Health, University of Lubumbashi, Lubumbashi, Democratic Republic of Congo \\ Email: *silungak@gmail.com
}

How to cite this paper: Bute, B.M., Djaile, M.K., Christian, K.W.K., Simon, I.K. and Benjamin, K.I. (2020) Determinants of Motivation among Health Care Providers, Case of Four General Referral Hospitals in Lubumbashi. Open Access Library Journal, 7: e6039.

https://doi.org/10.4236/oalib.1106039

Received: December 31, 2019

Accepted: January 14, 2020

Published: January 17, 2020

Copyright $\odot 2020$ by author(s) and Open Access Library Inc.

This work is licensed under the Creative Commons Attribution International License (CC BY 4.0).

http://creativecommons.org/licenses/by/4.0/

\begin{abstract}
Introduction: The objectives of our study were to determine providers by structure, to determine the providers by age, to make recommendations improve the motivation of the human resources and finally to determine the factors that influence the motivation of the personnel in the HGR of the city of Lubumbashi. Methodology: This is a cross-sectional analytical descriptive study of 152 care providers from four reference hospitals in Lubumbashi, surveyed prospectively, and based on a pre-established questionnaire. Data were analysed using SPSS 23 . The statistical associations were evaluated by determining the $\mathrm{p}$-value whose threshold was fixed at 0.05 , using the chi-square test. Results: In the majority, $27.63 \%$ of respondents were between 39 and 45 years old. The average age was $37.58 \pm 10.64$ years, the extremes with 21 and 69 years. There is no statistical relationship between on-the-job training and provider motivation ( $\mathrm{p}$-value greater than 0.05 ). Chi2 $=3.9 ; p=$ 0.06 . We noticed that $71.05 \%$ of respondents were in medical services with the majority being $15.79 \%$ in the Internal Medicine department. Conclusion: Improving working conditions is of paramount importance to improve the performance of healthcare providers and, consequently, the quality of care in our environment; thus, we believe that this should be done through the mechanization of health care providers, their provision of the risk premium and the encouragement of those who work overtime.
\end{abstract}

\section{Subject Areas}

Education, Public Health 


\section{Keywords}

Determinant, Motivation, Care Providers

\section{Introduction}

For several decades, according to Albouy quoted by Evainand et al. the control of health expenditure has become one of the main concerns of developed countries, particularly France because of the significant structural deficit of the Health Insurance. These expenditures, of which hospital care is one of the main drivers, are indeed growing steadily, although the pace has slowed in recent years. The determinants of this growth have been studied many times and three fundamental factors are often mentioned: changes in health status, standard of living and innovation. But other factors, related to the organization and regulation of the supply of care, also play a role in the increase of health expenditure [1].

In the Eastern Mediterranean Region, hospital mismanagement has been identified as one of the causes of poor performance, particularly in low- and lower-middle income countries. Inadequate management of human resources is a widespread problem, coupled with the absence of any incentive and reward system and any in-depth evaluation system. Improving hospital performance as part of improving the performance of the health system in general has been prioritized in the reform agenda of the countries of the Region. Many countries have developed programs to strengthen the skills of hospital leaders and put in place modern hospital management procedures that include making hospitals more self-reliant, allowing for greater management flexibility, improving health care systems, and improving hospital management information and enhancing their effectiveness [2].

\section{Methodology}

We conducted a descriptive cross-sectional analytical study or cross-sectional case-control, based on the determinants of the motivation of care providers in the Lubumbashi City HGRs, including the Kamalondo, Kampemba, Katuba and Kenya reference general hospitals. From December 1, 2018 to June 30, 2019. Data collection was prospective through a guided interview.

Our sampling was comprehensive and our sample size was 152 care providers. SPSS 23 software was used to analyze the data.

\section{Results}

In the majority, $27.63 \%$ of respondents were between 39 and 45 years old. The means age was $37.58 \pm 10.64$ years the extremes with 21 and 69 years.

The table above indicates that $71.05 \%$ of respondents were in medical services with the majority being $15.79 \%$ in the Internal Medicine department (Table 1 and Table 2, Table 3). 
Table 1. Distribution of respondents by age.

\begin{tabular}{ccc}
\hline Age (Years) & $\mathrm{N}$ & $(\%)$ \\
\hline $18-24$ & 13 & 8.6 \\
$25-31$ & 35 & 23 \\
$32-38$ & 30 & 19.7 \\
$39-45$ & 42 & 27.6 \\
$46-52$ & 12 & 7.9 \\
$53-59$ & 8 & 5.3 \\
$60-66$ & 5 & 3.3 \\
$67-73$ & 1 & 0.7 \\
No response & 6 & 3.9 \\
Total & 152 & 100 \\
\hline
\end{tabular}

Table 2. Distribution of respondents according to the services in which they work.

\begin{tabular}{|c|c|c|c|}
\hline \multicolumn{2}{|c|}{ SERVICE } & $\mathrm{N}$ & $\%$ \\
\hline \multirow{3}{*}{$\begin{array}{l}\text { Administrative } \\
\text { department }\end{array}$} & Administrative & 14 & 9.2 \\
\hline & Head of Nursing & 5 & 3.3 \\
\hline & Nurse holder & 1 & 0.7 \\
\hline \multirow{5}{*}{$\begin{array}{l}\text { Maintenance and } \\
\text { logistics service }\end{array}$} & Sub-total & 20 & 13.2 \\
\hline & ambulance & 1 & 0.7 \\
\hline & Maintenance & 1 & 0.7 \\
\hline & Reception & 3 & 1.9 \\
\hline & Hygiene and sanitation & 1 & 0.7 \\
\hline \multirow{4}{*}{ Paramedical service } & Sub-total & 6 & 3.9 \\
\hline & Laboratory & 14 & 9.2 \\
\hline & Radiology & 2 & 1.3 \\
\hline & Sub-total & 16 & 10.5 \\
\hline \multirow{15}{*}{ Medical service } & Dentisterie & 1 & 0.7 \\
\hline & Gynécologie-Obstétrique & 2 & 1.3 \\
\hline & Maternité & 17 & 11.2 \\
\hline & Médecine Interne & 24 & 15.8 \\
\hline & Nutrition & 3 & 1.9 \\
\hline & & 1 & 0.7 \\
\hline & Otorynolaryngology & 18 & 11.8 \\
\hline & pediatrics & 7 & 4.6 \\
\hline & Pharmacy & 10 & 6.6 \\
\hline & General medicine & 11 & 7.2 \\
\hline & Emergency room & 1 & 0.7 \\
\hline & Great Burn Center & 13 & 8.6 \\
\hline & Surgery & 108 & 71.1 \\
\hline & response & 2 & 1.3 \\
\hline & Total & 152 & 100 \\
\hline
\end{tabular}


Table 3. Distribution of respondents by their marital status.

\begin{tabular}{ccc}
\hline Marital status & N & $\%$ \\
\hline Single & 48 & 31.6 \\
Divorced & 2 & 1.3 \\
Married & 96 & 63.2 \\
Widow & 6 & 3.9 \\
Total & 152 & 100 \\
\hline
\end{tabular}

There is no statistical relationship between on-the-job training and provider motivation ( $\mathrm{p}$-value greater than 0.05 ). Chi2 $=3.9 ; p=0.06$.

The fact that working conditions are optimal to exercise is not statistically significant to the motivation of the providers ( $\mathrm{p}$-value greater than 0.05 ). Chi2 $=$ $0.01 ; p=0.9$.

We did not find a statistically significant link between workload and provider motivation ( $\mathrm{p}$-value greater than 0.05 ). Chi2 $=0.3 ; p=0.6$.

\section{Discussion}

In relation to age (Table 1 ), we found that $27.63 \%$ of respondents were between 39 and 45 years old. Our results are different from those found by some authors.

In relation to the service, Table 2 indicates that $71.05 \%$ of respondents were in medical services, with the majority being $15.79 \%$ in the Internal Medicine service. Our results are similar to those of Ndione [3].

We found that $75.66 \%$ (Table 4) were trained on the job. In addition, we found no statistically significant relationship between on-the-job training and provider motivation ( $p$-value greater than 0.05 ). A contradictory result was found in a study on work organization, in which it was found that employees who did not have sufficient information to do their job were more likely to be at risk of stress at work. [4] With the consequence, among other things, the reduction of the quality of the caregiver-patient relationship and the care [5]. Building the capacity of healthcare providers on specific issues is one of the key points of motivational frameworks [6].

The fact that working conditions are optimal to exercise is not statistically significant to the motivation of the providers ( $p$-value greater than 0.05) (Table 5).

Table 6 indicates that $63.16 \%$ of respondents considered the conditions of their work as not optimal. Moreover, the fact that the working conditions are optimal to exercise is not statistically significant with the motivation of the providers ( $p$-value greater than 0.05 ). This result is in contradiction with that in European studies which found that job satisfaction and stress reduction were significantly related to a better caregiver-patient relationship and a better quality of health care giving [7].

In the (Table 6) workload register, we found that $70.39 \%$ of respondents said they were overwhelmed by the burden of their work, this overflow was considered surplus among public sector health providers. Those in the private sector 
Table 4. Distribution of respondents by on-the-job training and provider motivation.

\begin{tabular}{cccc}
\hline \multirow{2}{*}{ On-the-job training } & \multicolumn{2}{c}{ Health workers'providers Motivation } & \\
\cline { 2 - 4 } & No & Yes & Total \\
\hline No & 11 & 24 & 35 \\
Yes & 18 & 94 & 112 \\
TOTAL & 29 & 118 & 147 \\
\hline
\end{tabular}

Table 5. Distribution of respondents according to the working conditions are optimal and the motivation of the health care providers.

\begin{tabular}{cccc}
\hline \multirow{2}{*}{$\begin{array}{c}\text { Optimal working conditions to } \\
\text { properly perform }\end{array}$} & \multicolumn{3}{c}{ Health workers'providers Motivation } \\
\cline { 2 - 4 } & No & yes & Total \\
\hline No & 19 & 76 & 95 \\
Yes & 10 & 42 & 52 \\
TOTAL & 29 & 118 & 147 \\
\hline
\end{tabular}

Table 6. Breakdown of respondents by workload overload and motivation of care providers.

\begin{tabular}{cccc}
\hline \multirow{2}{*}{ workload overload } & \multicolumn{3}{c}{ Health workers'providers Motivation } \\
\cline { 2 - 4 } & No & yes & Total \\
\hline No & 7 & 34 & 41 \\
Yes & 22 & 84 & 106 \\
TOTAL & 29 & 118 & 147 \\
\hline
\end{tabular}

[8]. In addition, $78.29 \%$ of respondents planned to work in a state structure. In bi-varied analysis, we did not note a statistically significant link with the motivation of providers ( $p$-value $<0.05)$. In a Tanzanian study, it was noted that a correct division of tasks results in a high level of nurse motivation [9], which, to some extent, ties in with the result of our study. Work overload has the direct effect of reducing thinking and cognitive decision-making, which impedes adherence behaviors and motivation of health care providers [10].

\section{Conclusions}

The objectives of our study were to determine the factors influencing the motivation of the staff in the HGR of the city of Lubumbashi.

Our cross-sectional study included 152 care providers from four reference hospitals in Lubumbashi, prospectively surveyed, on the basis of a questionnaire: The majority of the respondents were between $27.63 \%$.

In $71.05 \%$ of cases, the investigators carried out in medical services with the majority or $15.79 \%$ in the service of Internal Medicine. The bride and groom accounted for $63.16 \%$ of the cases.

There is no statistical relationship between on-the-job training and provider 
motivation ( $\mathrm{p}$-value greater than 0.05 ). Chi2 $=3.9 ; p=0.06$.

The fact that working conditions are optimal to exercise is not statistically significant to the motivation of the providers ( $p$-value greater than 0.05 ). Chi2 $=$ $0.01 ; p=0.9$.

An urgent need to improve working conditions is one of the conditions for the delivery of quality care.

\section{Conflicts of Interest}

The authors declare no conflicts of interest regarding the publication of this paper.

\section{References}

[1] Evain, F. and Yilmaz, E. (2019) Les déterminants de la rentabilité économique des établissements de santé. Econ. publique, 29, 305-316.

[2] OMS (2009) Document Technique: Améliorer la performance dans la région de la Méditerranée orientale.

[3] Ndione, A.G. (2010) Connaissances, attitudes et pratiques des soignants face aux risqsues liés à l'hépatite $\mathrm{B}$ au $\mathrm{CHU}$ de Fann.

[4] Gauthier, B. (2016) Qualité de vie au travail et environnement organisationnel: Etudes qualitatives et quantitatives sur les personnels en établissement de santé.

[5] Lightbown, N. and Spada, P.M. (2013) la place de la spiritualité dans les soins infirmiers: Une revue de littérature. How Lang. are Learn., 12, 27-40.

[6] JHPIEGO (2017) Guide d'examen et de planification pour la mise en œuvre des programmes de lutte contre le paludisme: Une approche des systèmes de santé.

[7] Aebischer, S. and Roussi, F. (2018) La perception de la satisfaction et du bien-être des patients aux urgences.

[8] JDS (2015) Dossier thématique. JDS, 4, 134.

[9] Margot, P. (1960) Le travail d'équipe auprès des malades: Ressource ou souffrance.

[10] Repond, T. (2012) Les facteurs de motivation infirmière assurant la pérennité d' un soin de qualité afin de prévenir les infections nosocomiales en milieu hospitalier Une revue de littérature étoffée Par. 